\title{
Rancang Bangun Sistem Informasi Pengelolaan Wisata Edukasi Berbasis Website Studi Kasus Kampung Marketer
}

\author{
Adi Pangestu' ${ }^{1}$ Lasmedi Afuan*2 \\ ${ }^{1,2}$ Jurusan Informatika, Fakultas Teknik, Universitas Jenderal Soedirman \\ Email: lasmedi.afuan@unsoed.ac.id
}

\begin{abstract}
Abstrak
Kampung marketer merupakan sebuah Organisasi Pendidikan Teknologi Informasi Digital Marketing, yang terletak di desa Tunjungmuli, Kecamatan Karangmoncol, Kabupaten Purbalingga. Kampung Marketer memiliki beberapa program kegiatan terkait pembelajaran Digital Marketing, salah satunya adalah program wisata edukasi. Permasalahan yang muncul pada pengelolaan program wisata edukasi adalah pengumpulan data pendaftar dan kurangnya informasi online mengenai wisata edukasi. Sebagai solusi dari permasalahan tersebut, pada penelitian ini mengembangkan Sistem Informasi Pengelolaan Wisata Edukasi Kampung Marketer. Sistem Informasi Pengelolaan Wisata Edukasi Kampung Marketer adalah sistem berbasis web yang digunakan untuk melakukan pengelolaan terhadap Program Wisata Edukasi Kampung Marketer. Adapun pengelolaan program diantaranya adalah pendaftaran, pembayaran, informasi, materi, dan evaluasi. Sistem Informasi Pengelolaan Wisata Edukasi ini dibuat dengan menggunakan metode Waterfall menggunakan Bahasa pemrograman PHP, database MySQL. Sistem ini dibentuk dengan tujuan untuk mengelola dan menyimpan data peserta secara terkomputerisasi. Sehingga semakin memudahkan pihak pengelola dan manajemen Kampung Marketer dalam mengelola wisata edukasi dengan efektif dan efisien.
\end{abstract}

Kata kunci: Digital Marketing, MySQL, PHP, Sistem Informasi, Waterfall, Wisata Edukasi.

\section{Design Of Management Information System Website-Based Education Tourism Case Study Of Kampung Marketer}

\begin{abstract}
Kampung Marketer is a Digital Marketing Information Technology Education Organization located in Tunjungmuli Village, Karangmoncol District, Purbalingga Regency. Kampung Marketer has several activity programs related to Digital Marketing learning, an educational tourism program. The problems that arise in the management of educational tourism programs are collecting registrant data and the lack of online information regarding educational tourism. As a solution to these problems, this study developed an Information System for the Management of Educational Tourism in Kampung Marketer. Kampung Marketer Tourism Education Management Information System is a web-based system used to manage the Kampung Marketer Education Tourism Tourism Program. The program management includes registration, payment, information, materials, and evaluation. The Education Tourism Management Information System was created using the Waterfall method using the MySQL database's PHP programming language. This system was formed to manage and store computerized participant data. They are making it easier for the management and management of Kampung Marketer to manage educational tours effectively and efficiently..
\end{abstract}

Keywords: Digital Marketing, MySQL, PHP, Informastion System, Waterfall, Tourism Education.

\section{PENDAHULUAN}

Perkembangan teknologi informasi maju dengan begitu pesatnya[1] dan telah memasuki berbagai lini kehidupan manusia. Teknologi telah menghasilkan layanan-layanan secara digital yang mudah diakses dan memiliki jaringan yang luas. Teknologi diharapkan dapat membantu khalayak ramai mempermudah kebutuhannya, memicu setiap orang, kelompok, atau lembaga mulai bergerak untuk dapat menyediakan sistemsistem yang dibutuhkan publik, berbagai sistem dan aplikasi telah dikembangkan dalam rangka memberikan bantuan dan layanan kepada publik diantaranya yang dikembangkan seperti aplikasi promosi wisata di Banyumas[1], sistem informasi pendataan laporan kerja praktek[2], aplikasi layanan untuk jasa laundri[3][4], 
aplikasi market place percetakan[5] dan aplikasi lain[6][7][8][9]. Aplikasi-aplikasi tersebut dikembangkan dengan tujuan untuk mempermudah dalam memberikan pelayanan kepada pengguna.

Kampung marketer merupakan sebuah Organisasi Pendidikan Teknologi Informasi Digital Marketing, yang terletak di desa Tunjungmuli, Kecamatan Karangmoncol, Kabupaten Purbalingga. Kampung Marketer didirikan oleh Nofi Bayu Darmawan, yang awalnya bernama Digital Purbalingga pada tahun 2013, dan kemudian pada tahun 2017 berubah menjadi Kampung Marketer. Kampung Marketer memiliki beberapa program kegiatan terkait pembelajaran Digital Marketing, salah satunya adalah program Wisata Edukasi.

Wisata edukasi merupakan suatu program rekreasi di pedesaan yang dikombinasikan dengan aktivitas edukasi atau pendidikan. Pada kegiatan wisata edukasi, peserta akan diajak untuk berwisata sekaligus mendapatkan pembelajaran tentang digital marketing. Calon peserta yang ingin mengikuti program ini, harus terlebih dahulu melakukan pendaftaran. Karena kuota peserta yang terbatas sehingga perlu adanya pengelolaan data dari para calon peserta Wisata Edukasi. Proses manual menjadi kendala dalam mengumpulkan data pendaftar, sehingga masih perlu adanya perbaikan sistem dalam pendaftaran Wisata Edukasi. Pemberian Informasi terkait Wisata Edukasi juga sangat penting agar masyarakat umum bisa lebih mengetahui dan tertarik terhadap Program Wisata Edukasi Kampung Marketer.

Oleh karena itu, pada penelitian ini mengembangkan Sistem Informasi Pengelolaan Wisata Edukasi Kampung Marketer Berbasis Web agar dapat meningkatkan kinerja pengelola untuk mengolah data dan informasi yang dimiliki agar lebih akurat dan efisien, maupun dapat meningkatkan pelayanan kepada masyarakat yang mengikuti program wisata edukasi.

\section{TINJAUAN PUSTAKA}

\subsection{Model Waterfall}

Model waterfall adalah model klasik yang bersifat sistematis, berurutan dalam membangun software[10][11]. Nama model ini sebenarnya adalah "Linear Sequential Model". Model ini sering disebut dengan "classic life cycle" atau model Waterfall. Model ini termasuk ke dalam model umum pada rekayasa perangkat lunak dan pertama kali diperkenalkan oleh Winston Royce sekitar tahun 1970, sehingga sering dianggap kuno, tetapi merupakan model yang paling banyak dipakai di dalam Software Engineering (SE). Model ini melakukan pendekatan secara sistematis dan berurutan seperti yang dapat dilihat pada Gambar 1.

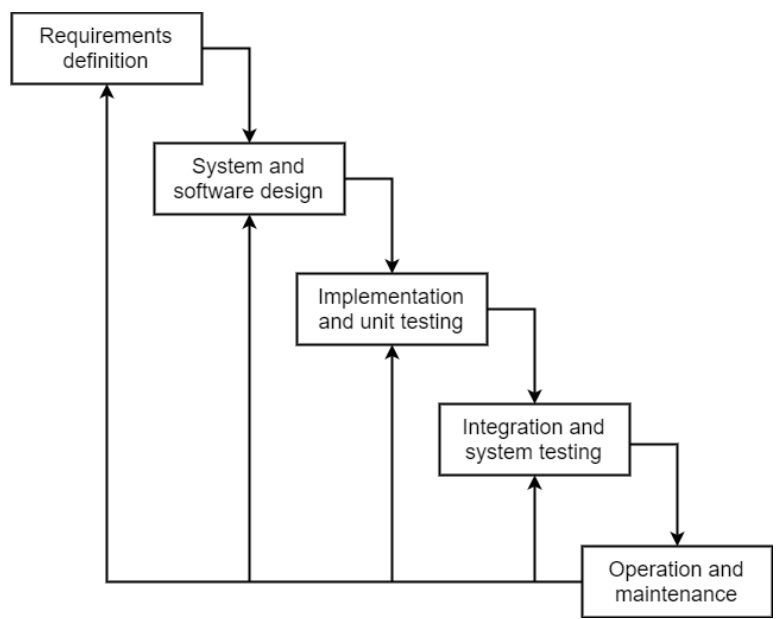

Gambar 1. Metode waterfall [1]

\subsection{Basis Data}

Basis data merupakan kumpulan terorganisasi dari data yang berhubungan sedemikian rupa sehingga mudah disimpan, dimanipulasi, serta dipanggil oleh pengguna. Terminologi hubungan berarti data mendeskripsikan domain (ranah) tertentu sehingga pengguna mudah untuk mendapatkan jawaban atas pertanyaan yang diajukannya ke basis data tersebut[12].

\subsection{Database Management System (DBMS)}

Database Management System (DBMS) adalah perangkat lunak sistem yang memungkinkan para pengguna membuat, memelihara, mengontrol, dan mengakses basis data dengan cara yang praktis dan efisien. DBMS 
dapat digunakan untuk mengakomodasikan berbagai macam pemakai yang memiliki kebutuhan akses yang berbeda-beda. Macam-macam DBMS yaitu MySQL, IBM DB2, Oracle Database, Sybase, dan lain-lain[13].

\subsection{Bahasa Basis Data (Database Language)}

Menurut ANSI (American National Standards Institute), SQL atau Structured Query Language merupakan bahasa standar untuk sistem manajemen basis data relasional. Secara umum, bahasa SQL memiliki beberapa bagian penting, yaitu:[12]

1) Data Definition Language (DDL)

SQL DDL menyediakan perintah-perintah untuk mendefinisikan skema relasi, menghapus relasi, serta memodifikasi skema relasi.

2) Data Manipulation Language (DML)

SQL DML mencakup bahasa SQL untuk menyisipkan rekaman pada relasi, menghapus rekaman pada relasi, serta memodifikasi rekaman pada relasi

3) View Definition

SQL memuat perintah-perintah untuk mendefinisikan tampilan-tampilan (view) yang dikehendaki pengguna.

4) Transaction Control

SQL memuat perintah-perintah untuk menspesifikasi awal dan akhir suatu transaksi.

5) Embedded $S Q L$ dan Dynamic $S Q L$

Terminologi ini mencakup kemampuan SQL untuk disisipkan pada beberapa bahasa pemrograman, misalnya pada Visual BASIC, Delphi, C/C++, Java, dan sebagainya.

6) Integrity

SQL DDL mencakup perintah-perintah untuk menspesifikasi batasan-batasan integritas.

7) Authorization

SQL DDL mencakup perintah-perintah untuk membatasi akses pada basis data demi alasan keamanan.

\subsection{Aplikasi Berbasis Website (Aplikasi Web)}

Suatu aplikasi web (Web Application) atau sering disingkat WebApp adalah suatu aplikasi yang diakses menggunakan penjelajah web melalui suatu jaringan seperti internet atau Intranet.

Aplikasi web juga merupakan suatu aplikasi perangkat lunak komputer yang dikodekan dalam bahasa yang didukung penjelajah web (Seperti HTML, JavaScript, AJAX, Java, dan lain-lain) dan bergantung pada penjelajah tersebut untuk menampilkan aplikasi.

\subsection{Bahasa Pemrograman}

Pengembangan aplikasi ini menggunakan beberapa bahasa pemrograman tingkat tinggi, diantaranya adalah sebagai berikut:

\section{Hyper Text Markup Language (HTML)}

HTML (Hyper Text Markup Language) adalah sebuah bahasa pemrograman atau file teks yang berisi tag-tag markup yang berguna untuk memberitahukan browser bagaimana harus menampilkan sebuah halaman web. Sebuah file HTML harus memiliki ekstensi htm atau html. HTML merupakan bahasa standar yang digunakan oleh browser internet untuk membuat halaman dan dokumen pada sebuah web yang kemudian dapat diakses dan dibaca layaknya sebuah artikel. HTML juga dapat digunakan sebagai link antara file-file dalam situs atau dalam komputer dengan menggunakan localhost, atau link yang menghubungkan antar situs dalam dunia internet[14].

PHP

PHP (Hypertext Preprocessor) merupakan sebuah bahasa script yang ditanam di sisi server. Pada penerapannya, PHP biasanya menyatu dengan HTML dan dijalankan pada server side, sehingga semua sintaks yang kita berikan akan sepenuhnya dijalankan pada server, sedangkan yang dikirimkan ke browser hanya hasil dari pengolahan sintaks yang telah diolah di sisi server[14].

\section{Cascading Style Sheet (CSS)}

CSS (Cascading Style Sheet) adalah suatu teknologi bahasa pemrograman web yang digunakan untuk mengendalikan dan membangun berbagai komponen dalam web sehingga tampilan web akan lebih indah, rapi, terstruktur, dan seragam[14]. 
Javascript

JavaScript adalah bahasa pemrograman yang terintegrasi langsung dengan html yang digunakan untuk membuat web lebih dinamis dan interaktif[14].

JQuery

JQuery adalah pustaka atau library JavaScript yang menekankan pada interaksi antara JavaScript dan HTML [14]. JQuery memudahkan dengan dukungan fasilitas yang lengkap dan proses pembuatan plugin JQuery juga cukup mudah. JQuery disimpan sebagai file JavaScript tunggal yang berisi semua metode JQuery.

\section{METODE PENELITIAN}

Metode penelitian yang digunakan pada penelitian ini dapat dilihat pada Gambar 2. Setiap tahapan memiliki kegiatan yang harus diselesaikan.

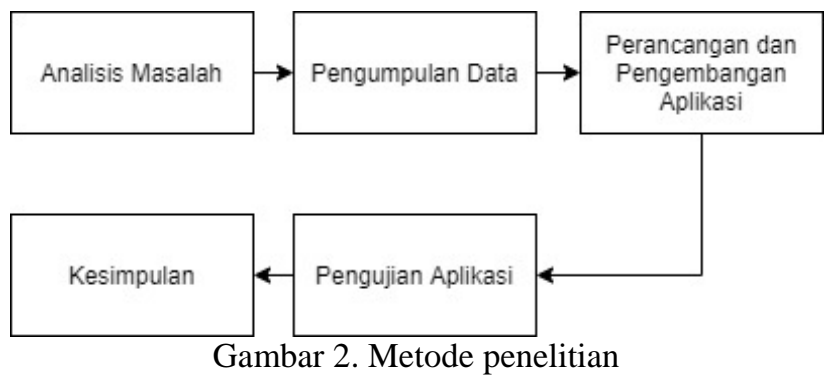

\subsection{Analisis Masalah}

Pada tahapan analisis masalah digunakan untuk mengetahui permasalahan-permasalahan yang terjadi pada penelitian ini.

\subsection{Pengumpulan Data}

Pengumpulan data dilakukan dengan menggunakan metode wawancara dan Observasi. Dalam perancangan dan pembuatan sistem informasi pengelolaan wisata edukasi, wawancara dilakukan kepada Mas Eko Sulistyono selaku Public Relation dalam bidang Growth Kampung Marketer yang berbagi mengenai Gambaran Kegiatan Wisata Edukasi dan memberikan gambaran umum sistem yang akan dibuat. Observasi dilakukan melalui pengamatan secara langsung di lapangan. Dalam hal ini, peneliti memerlukan informasi mengenai wisata edukasi. Oleh karena itu perlu dilakukan observasi untuk mendapatkan data yang diperlukan.

\subsection{Perancangan dan pengembangan Aplikasi}

Perancangan aplikasi Layanan Penyedia Jasa ini, perancangan sistem menggunakan metode Waterfall. Pada metode Waterfall terdapat 5 tahapan, yaitu tahap requirements definition (analisis kebutuhan), system and software design (desain sistem), implementation and unit testing (penulisan kode program), integration and system testing (pengujian sistem), operation and maintenance (penerapan dan pemeliharaan).

1) Tahap Requirements Definition

Tahap requirements definition atau analisis kebutuhan merupakan tahap pertama yang menjadi dasar proses pembuatan aplikasi. Tahap analisis dilakukan dengan cara wawancara dan observasi. Setelah dilakukan analisis maka akan terbentuk kebutuhan-kebutuhan pengguna atau user requirement.

2) Tahap System and Software Design

Tahap system and software design atau desain sistem merupakan tahap penyusunan proses, data, aliran proses dan hubungan antar data yang paling optimal untuk menjalankan proses dan memenuhi kebutuhan pengguna sesuai dengan hasil analisa kebutuhan. Pada tahap ini akan menghasilkan dua desain, yaitu desain data dan desain antarmuka. Desain data akan menghasilkan DFD (Data Flow Diagram) dan ERD (Entity Relational Diagram), sedangkan desain antarmuka akan menghasilkan desain antarmuka yang akan diimplementasikan ke sistem

3) Tahap Implementation and Unit Testing

Tahap implementation and unit testing atau penulisan kode program merupakan tahap penerjemahan desain sistem yang telah dibuat ke dalam bentuk perintah-perintah yang dimengerti komputer menggunakan bahasa pemrograman dan basis data tertentu. Tahap ini merupakan implementasi dari tahap desain sistem. Aplikasi Layanan Penyedia Jasa ini menggunakan bahasa pemrograman PHP dan basis data $M y S Q L$. 
4) Tahap Integration and System Testing

Tahap integration and system testing atau pengujian sistem merupakan tahap untuk menguji sistem yang dibuat untuk mengetahui kekurangan pada sistem sebelum digunakan. Pengujian ini dilakukan oleh pembuat sistem dan pengguna sistem. Apabila ketika pengujian ditemukan kesalahan maka akan disempurnakan kembali oleh mahasiswa sampai sistem sesuai dengan kebutuhan pengguna..

5) Tahap Operation and Maintenance

Tahap operation and maintenance atau penerapan dan pemeliharaan merupakan tahap menerapkan sistem yang telah dibuat dan diuji ke dalam lingkungan instansi. Pemeliharaan dilakukan agar penggunaan dari sistem dapat terus optimal dan meminimalisir kegagalan sistem. Perawatan dapat dilakukan secara berkala terhadap sistem, basis data, dan komponen pendukungnya. Perawatan juga dapat dilakukan dengan membuat petunjuk penggunaan.

\subsection{Pengujian Sistem Informasi}

Pengujian sistem informasi bertujuan untuk mengevaluasi sebuah perangkat lunak baik dari sisi fungsionalitas maupun kinerja dari perangkat lunak tersebut. Pengujian dilakukan dengan menggunakan metode BlackBox testing untuk menguji fungsionalitas dari aplikasi yang telah dikembangkan.

\section{HASIL DAN PEMBAHASAN}

\subsection{Tahap Analisis}

Tahap analisis (Analysis) merupakan tahap awal yang dilakukan dalam pengembangan sistem informasi pengelolaan wisata edukasi Kampung Marketer. Tahap ini dilakukan untuk mengidentifikasi permasalahan dan kebutuhan terkait sistem yang akan dibuat. Tahap analisis ini dilakukan dengan cara wawancara. Wawancara dilakukan kepada narasumber, yaitu Eko Sulistyono selaku Public Relation Kampung Marketer.

a. Identifikasi Pengguna

Pengguna dari Sistem Informasi Pengelolaan Wisata Edukasi ini terdiri dari 4 jenis pengguna yaitu sebagai berikut:

\section{- Kabid Growth Kampung Marketer}

Kabid Growth merupakan pengguna yang mempunyai kedudukan cukup tinggi di dalam sistem. Kabid Growth berperan sebagai orang yang meinjau dan mengawasi terkait program Wisata Edukasi Kampung Marketer. Kabid Growth memiliki akses ke seluruh komponen yang ada di dalam sistem seperti : login, mengelola data user, mengelola file, menambahkan admin, mencetak laporan dll

- Admin

Admin adalah pengguna yang berperan sebagai orang yang mengelola Sistem Informasi Pengelolaan Wisata Edukasi, memiliki hak akses seperti Kelola data user, konfirmasi peserta, login, menambahkan materi, mencetak laporan dll.

- Calon Peserta/Peserta

Calon Peserta adalah pengguna yang telah melakukan pendaftaran dalam sistem namun belum melakukan pembayaran. Dan setelah melakukan pembayaran dan dikonfirmasi oleh admin Calon peserta berubah statusnya menjadi peserta yang terkonfirmasi untuk mengikuti program wisata edukasi.adapun calon peserta/peserta memiliki hak akses melakukan pendaftaran, login, melakukan upload bukti pembayaran, dan setelah dikonfirmasi menjadi peserta memiliki hak akses untuk mendownload materi serta memberi evaluasi terhadap program wisata edukasi melalui sistem.

b. Identifikasi Kebutuhan Pengguna

Dari identifikasi peran pengguna yang sudah dijabarkan dapat diidentifikasi kebutuhan masing - masing pengguna. User Requirement Spesification (URS) ditampilkan pada Tabel 1.

c. Identifikasi Kebutuhan Sistem

Berdasarkan identifikasi kebutuhan pengguna yang sudah dijabarkan dapat diidentifikasi kebutuhan yang harus dipenuhi oleh sistem. System Requirement Spesification (SRS) ditampilkan pada Tabel 2.

\subsection{Tahap Desain}

Tahap desain merupakan tahap kedua yang dilakukan ketika tahap analisis sudah selesai dilakukan. Tahap desain ini bertujuan untuk membuat acuan dan gambaran tentang bagaimana sistem akan dikembangkan. 
Hal ini sangat penting dikarenakan pengembangan sistem akan menjadi lebih terarah, sehingga nantinya sistem akan menghasilkan keluaran (output) yang diharapkan. Terdapat tiga hal yang dilakukan dalam tahap desain, yaitu desain aliran data, desain database (basisdata), dan desain user interface (antarmuka).

a. Desain Aliran Data

Desain aliran data merupakan salah satu tahapan dalam tahap desain. Dalam tahap ini akan digambarkan mengenai bagaimana data-data yang digunakan dalam sistem di proses menjadi informasi yang diinginkan. Penggambaran aliran dalam sistem menggunakan Data Flow Diagram (DFD) yang dapat dikembangkan menjadi beberapa level sesuai kebutuhan. Dalam kasus ini (Sistem Informasi Pengelolaan Wisata Edukasi Kampung Marketer), aliran data digambarkan ke dalam tiga level.

Tabel 1. User Rewiurement Spesification

\begin{tabular}{|c|c|c|}
\hline Pengguna & Kebutuhan & Kode URS \\
\hline \multirow[t]{13}{*}{ Kabid Growth } & Melakukan Login & URS-SIMWE-1 \\
\hline & Tambah Admin & URS-SIMWE-2 \\
\hline & $\begin{array}{l}\text { Konfirmasi Calon } \\
\text { Peserta }\end{array}$ & URS-SIMWE-3 \\
\hline & Lihat data peserta & URS-SIMWE-4 \\
\hline & Edit data peserta & URS-SIMWE-5 \\
\hline & Hapus data peserta & URS-SIMWE-6 \\
\hline & Lihat Pembayaran & URS-SIMWE-7 \\
\hline & Tambah materi & URS-SIMWE-8 \\
\hline & Edit materi & URS-SIMWE-9 \\
\hline & Hapus materi & URS-SIMWE-10 \\
\hline & Lihat Pembayaran & URS-SIMWE-11 \\
\hline & Lihat hasil evaluasi & URS-SIMWE-12 \\
\hline & Cetak laporan & URS-SIMWE-13 \\
\hline \multirow[t]{12}{*}{ Admin } & Melakukan login & URS-SIMWE-13 \\
\hline & $\begin{array}{l}\text { Konfirmasi Calon } \\
\text { Peserta }\end{array}$ & URS-SIMWE-14 \\
\hline & Lihat data peserta & URS-SIMWE-15 \\
\hline & Edit data peserta & URS-SIMWE-16 \\
\hline & Hapus data peserta & URS-SIMWE-17 \\
\hline & Lihat Pembayaran & URS-SIMWE-18 \\
\hline & Tambah materi & URS-SIMWE-19 \\
\hline & Edit materi & URS-SIMWE-20 \\
\hline & Hapus materi & URS-SIMWE-21 \\
\hline & Lihat pembayaran & URS-SIMWE-22 \\
\hline & Lihat hasil evaluasi & URS-SIMWE-23 \\
\hline & Cetak laporan & URS-SIMWE-24 \\
\hline \multirow[t]{4}{*}{ Peserta } & Pendaftaran & URS-SIMWE-25 \\
\hline & Melakukan login & URS-SIMWE-26 \\
\hline & Upload pembayaran & URS-SIMWE-27 \\
\hline & $\begin{array}{l}\text { Mendownload } \\
\text { materi }\end{array}$ & URS-SIMWE-28 \\
\hline
\end{tabular}

\section{Data Flow Diagram Level 0}

Gambar 3 merupakan Diagram konteks atau Data Flow Diagram Level 0 merupakan diagram yang menggambarkan data-data yang mengalir dari dan ke dalam sistem secara umum. Diagram konteks juga menggambarkan entitas luar atau external entity yang terlibat dalam aliran data pada sistem, baik mengirim/memberikan data, menerima data, maupun keduanya. Terdapat 3 pengguna dari Sistem Pengelolaan Wisata Edukasi. 3 pengguna yang dapat melakukan login yaitu Admin, Kabid Growth dan Peserta. 
Tabel 2. System Requirement Spesification

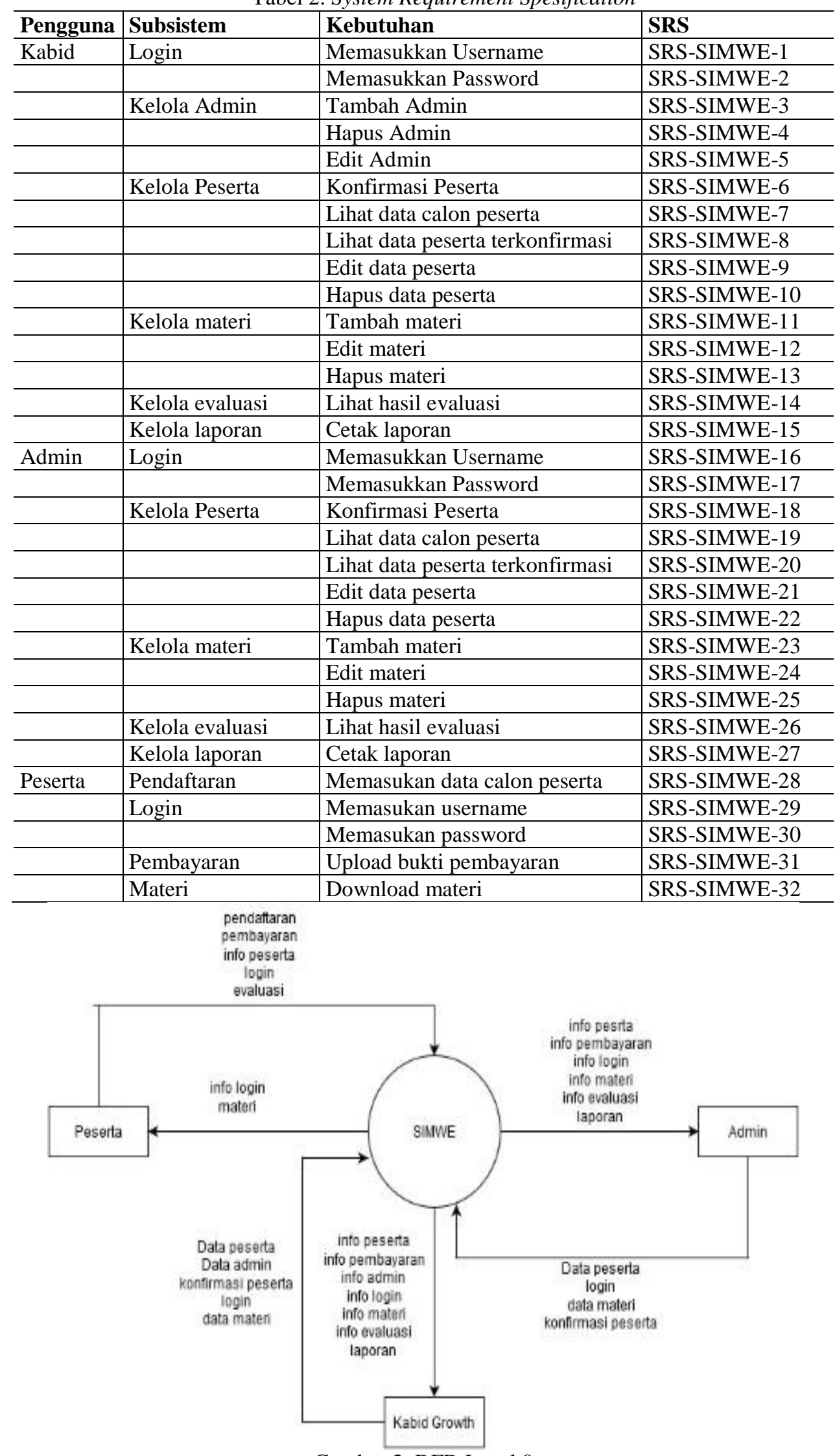

Gambar 3. DFD Level 0 


\section{Data Flow Diagram Level 1}

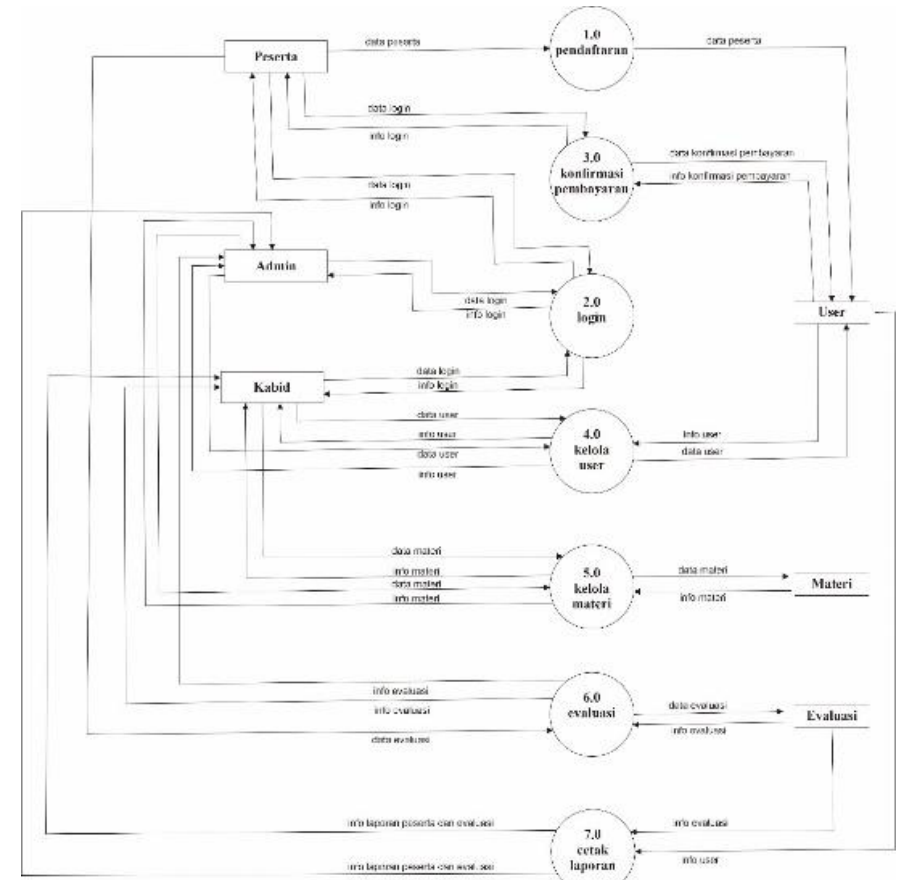

Gambar 4. DFD Level 1

DFD Level 1 merupakan penjabaran dari DFD Level 0 (Diagram Konteks). Dalam DFD Level 1 ini dijelaskan secara rinci dari kerja sistem dengan membagi sistem menjadi beberapa proses yang saling berkaitan.

\section{Entity Relationship Diagram (ERD)}

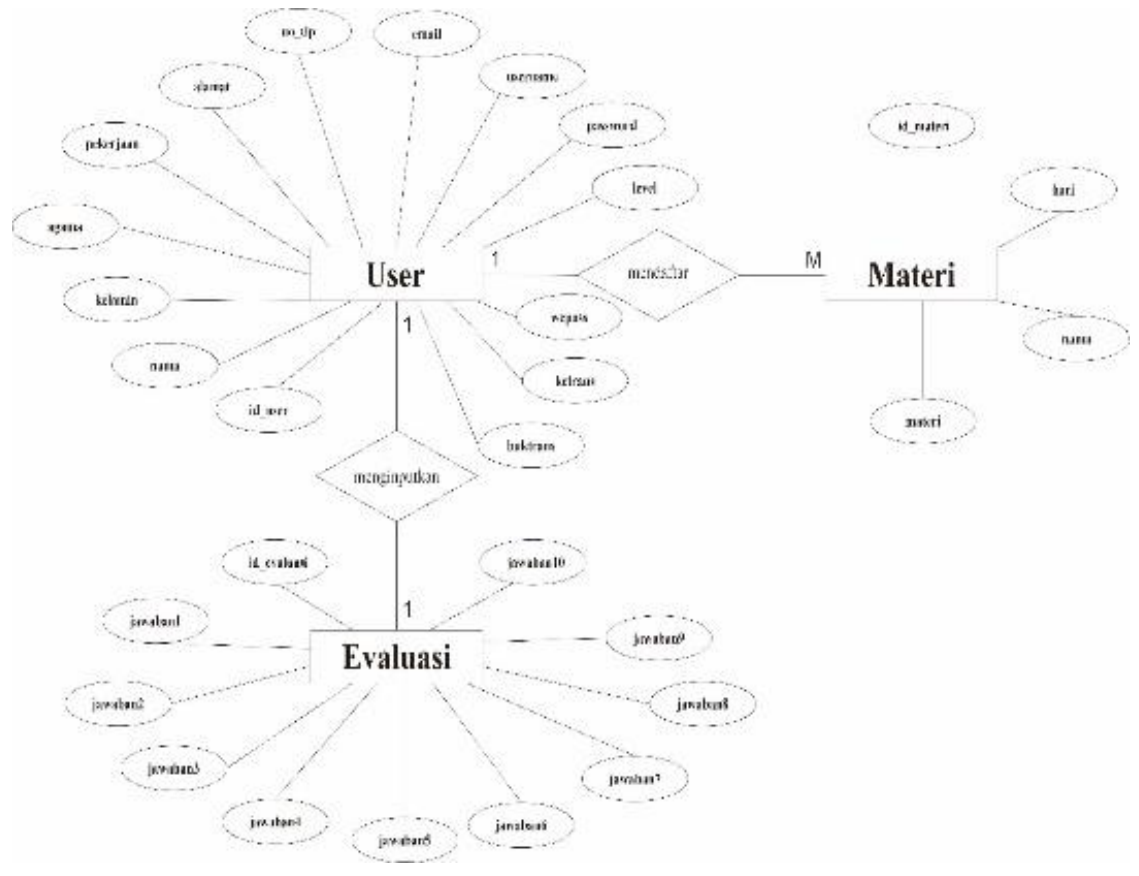

Gambar 5. ERD

Berdasarkan Gambar 5, terdapat 3 entitas yang saling berhubungan yaitu user, evaluasi, dan materi. Kardinalitas dari tiap entitas akan di jelaskan sebagai berikut: 
1. User dengan Evaluasi

Relasi yang terjadi antara User dan Evaluasi adalah user dapat menginputkan evaluasi ke dalam sistem. Kardinalitas dari relasi ini adalah one to one karena satu user hanya bisa memberikan evaluasi sebanyak satu kali.

2. User dengan Materi

Relasi yang terjadi antara User dan Materi adalah user mendaftar terlebih dahulu untuk bisa mendapatkan materi dari dalam sistem. Kardinalitas dari relasi ini adalah one to many karena satu user bisa mendapatkan banyak materi.

\subsection{Perancangan Tabel}

Perancangan tabel yang ada pada basis data yang digunakan pada Sistem Informasi Pengelolaan Wisata Edukasi adalah sebagai berikut.

1) Tabel User

Tabel user merupakan tabel yang berisi data-data login dan useer seperti id_user, nama, kelamin, agama, pekerjaan, alamat, no_tlp, email, username, password, level, wepass, ketrans, dan buktrans. Tabel User ditunjukkan pada Tabel 3.

Tabel 3. Tabel User

\begin{tabular}{l|l|l}
\hline Nama & Tipe & Key \\
\hline id_user & Int & Primary \\
\hline nama & varchar(30) & - \\
\hline kelamin & varchar(10) & - \\
\hline agama & varchar(10) & - \\
\hline pekerjaan & varchar(30) & - \\
\hline alamat & varchar(250) & - \\
\hline no_tlp & varchar(15) & - \\
\hline email & varchar(30) & - \\
\hline username & varchar(30) & - \\
\hline password & varchar(30) & - \\
\hline level & varchar(20) & - \\
\hline wepass & varchar(20) & - \\
\hline ketrans & varchar(200) & - \\
\hline buktrans & text & - \\
\hline
\end{tabular}

Tabel 4. Tabel Materi

\begin{tabular}{l|l|l}
\hline Nama & Tipe & Key \\
\hline id_materi & int & Primary \\
\hline hari & varchar(10) & - \\
\hline nama & varchar(100) & - \\
\hline materi & text & - \\
\hline
\end{tabular}

Tabel 5. Tabel Evaluasi

\begin{tabular}{l|l|l}
\hline Nama & Type & Key \\
\hline Id_evaluasi & Int(10) & primary \\
\hline Jawaban1 & Varchar(100) & - \\
\hline Jawaban2 & Varchar(100) & - \\
\hline Jawaban3 & Varchar(100) & - \\
\hline Jawaban4 & Varchar(100) & - \\
\hline Jawaban5 & Varchar(100) & - \\
\hline Jawaban6 & Varchar(100) & - \\
\hline Jawaban7 & Varchar(100) & - \\
\hline Jawaban8 & Varchar(100) & - \\
\hline Jawaban9 & Varchar(100) & - \\
\hline Jawaban10 & Varchar(100) & - \\
\hline
\end{tabular}


2) Tabel Materi

Tabel Materi merupakan tabel yang digunakan untuk menyimpan data - data materi Wisata Edukasi. Tabel materi dapat dilihat pada Tabel 4.

3) Tabel Evaluasi

Tabel Evaluasi merupakan tabel yang digunakan untuk menyimpan data Evaluasi yang diinputkan oleh peserta. Tabel Evaluasi dapat dilihat pada Tabel 5.

\subsection{Desain Antar Muka Dan Implementasi}

Pada Tahap Ini dirancangan halaman antarmuka pengguna dari sistem pewisata edukasi ngelolaan yang akan dikembangkan. Desain ini akan menjadi dasar dalam implementasi aplikasi agar dapat agar sesuai dengan keinginan pengguna. Berikut adalah tampilan halaman Awal Sistem Pengelolaan Wisata Edukasi yang ditunjukkan pada Gambar 6, tampilan halaman Peserta Wisata Edukasi yang ditunjukkan oleh Gambar 7, tampilan halaman Admin yang ditunjukkan oleh Gambar 7 dan tampilan halaman Kabid yang ditunjukkan oleh Gambar 8.

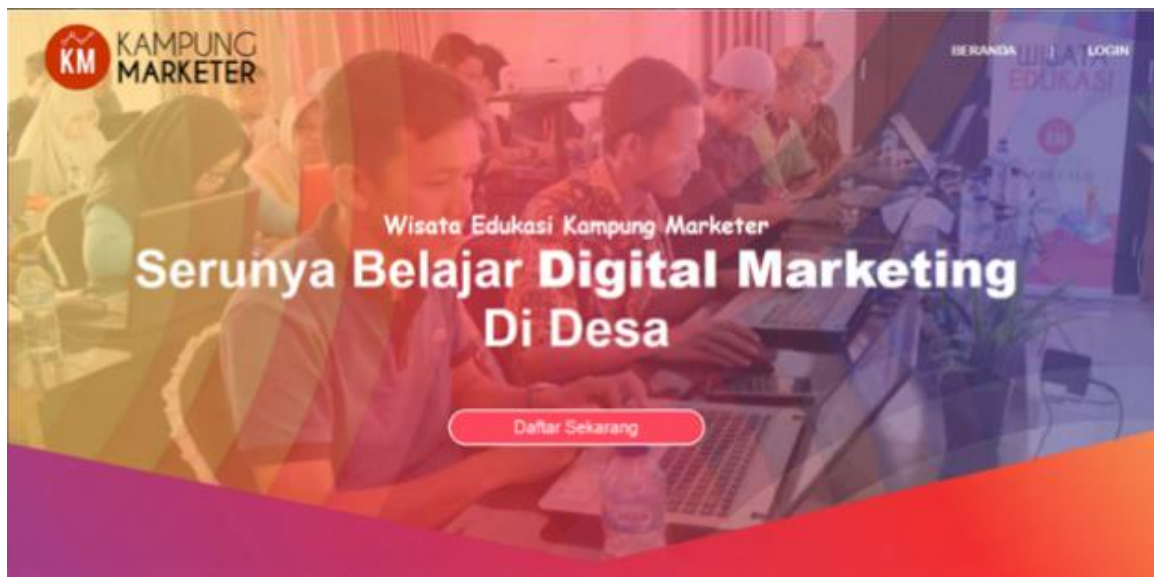

Gambar 6. Tampilan Halaman Awal

Halaman Awal Sistem Pengelolaan Wisata Edukasi merupakan halaman yang pertama kali muncul Ketika mengakses sistem informasi ini. Halaman awal berisi informasi terkait Program Wisata Edukasi. Tampilan dari Halaman Awal ditunjukkan pada Gambar 6.

Halaman Peserta merupakan halaman yang ditampilkan kepada Peserta yang sudah mendaftar dan sudah dikonfirmasi pembayarannya. Dengan melakukan login terlebih dahulu untuk mengakses halaman tersebut. Tampilan dari Halaman Peserta ditunjukkan pada Gambar 6.

Halaman Admin merupakan halaman yang hanya bisa diakses oleh admin setelah melakukan login terlebih dahulu. Dan dihalaman admin, admin bisa mengelola data dan informasi dari program Wisata Edukasi. Tampilan dari Halaman Admin ditunjukkan pada Gambar 7.

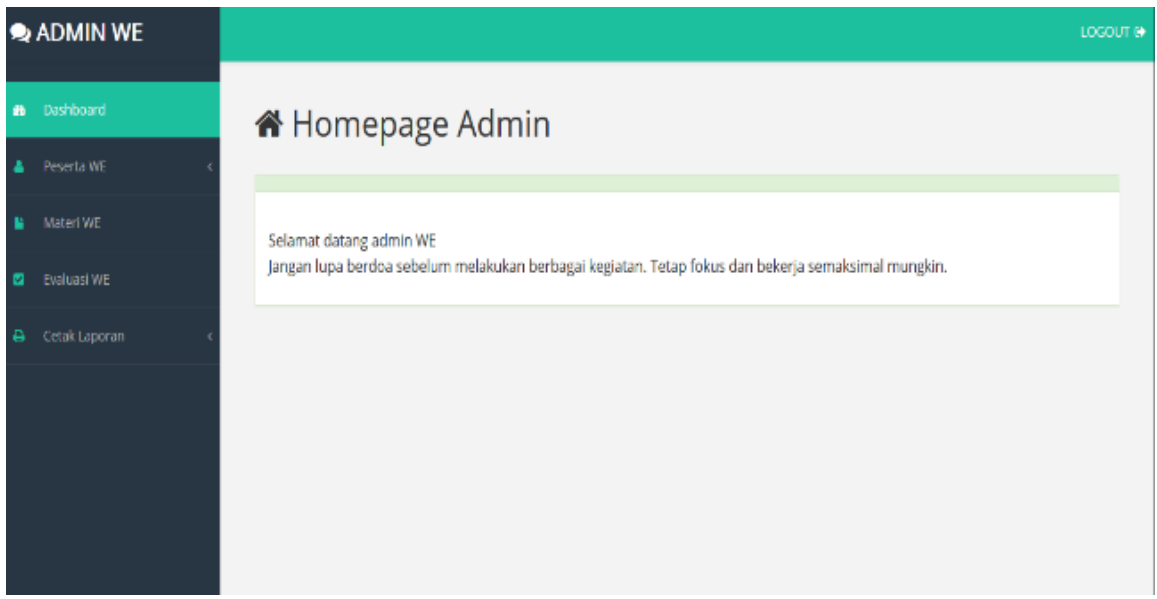

Gambar 7. Tampilan Halaman Admin 


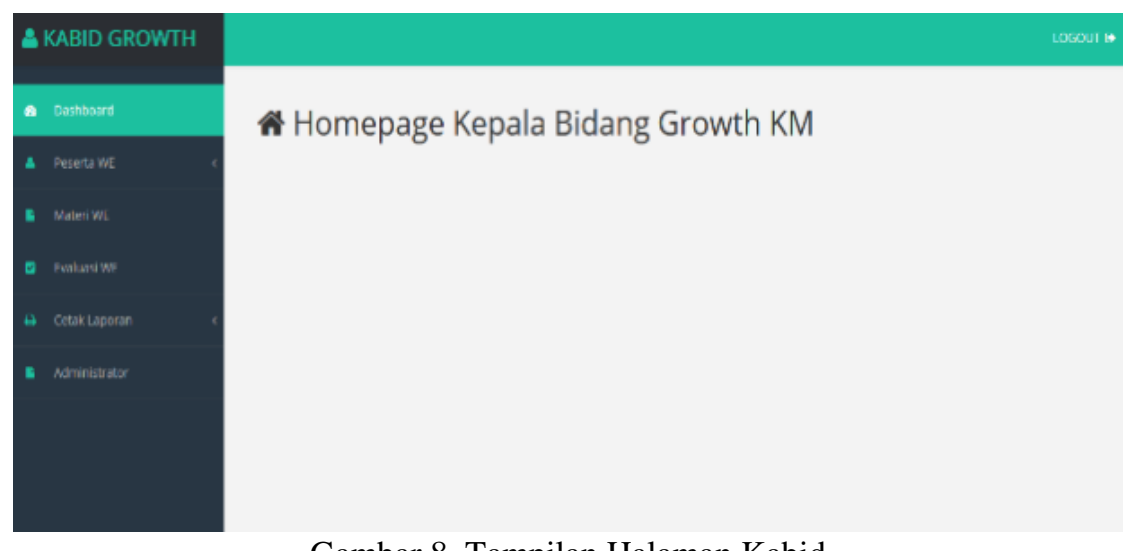

Gambar 8. Tampilan Halaman Kabid

Tabel 6 .Tabel Rencana Pengujian

\begin{tabular}{l|l}
\hline \multicolumn{1}{c|}{ User Requirement } & \multicolumn{1}{c}{ Keterangan } \\
\hline URS-SIMWE-1 & Melakukan Login \\
\hline URS-SIMWE-2 & Tambah Admin \\
\hline URS-SIMWE-3 & Konfirmasi Calon Peserta \\
\hline URS-SIMWE-4 & Lihat data peserta \\
\hline URS-SIMWE-5 & Edit data peserta \\
\hline URS-SIMWE-6 & Hapus data peserta \\
\hline URS-SIMWE-7 & Lihat Pembayaran \\
\hline URS-SIMWE-8 & Tambah materi \\
\hline URS-SIMWE-9 & Edit materi \\
\hline URS-SIMWE-10 & Hapus materi \\
\hline URS-SIMWE-11 & Lihat Pembayaran \\
\hline URS-SIMWE-12 & Lihat hasil evaluasi \\
\hline URS-SIMWE-13 & Cetak laporan \\
\hline URS-SIMWE-13 & Melakukan login \\
\hline URS-SIMWE-14 & Konfirmasi Calon Peserta \\
\hline URS-SIMWE-15 & Lihat data peserta \\
\hline URS-SIMWE-16 & Edit data peserta \\
\hline URS-SIMWE-17 & Hapus data peserta \\
\hline URS-SIMWE-18 & Lihat Pembayaran \\
\hline URS-SIMWE-19 & Tambah materi \\
\hline URS-SIMWE-20 & Edit materi \\
\hline URS-SIMWE-21 & Hapus materi \\
\hline URS-SIMWE-22 & Lihat pembayaran \\
\hline URS-SIMWE-23 & Lihat hasil evaluasi \\
\hline URS-SIMWE-24 & Cetak laporan \\
\hline URS-SIMWE-25 & Pendaftaran \\
\hline URS-SIMWE-26 & Melakukan login \\
\hline URS-SIMWE-28 & \\
\hline &
\end{tabular}


Halaman Kabid merupakan halaman yang hanya bisa diakses oleh Kabid setelah melakukan login terlebih dahulu. Dan dihalaman Kabid, Kabid bisa mengelola data dan informasi dari program Wisata Edukasi. Yang membedakan halaman kabid dan halaman admin adalah di halaman kabid, kabid bisa mengelola data admin, seperti menambahakan admin, menghapus admin, menghapus data, dll. Tampilan dari Halaman Kabid ditunjukkan pada Gambar 8.

\subsection{Pengujian}

Tahap pengujuan sistem dilakukan dengan menggunakan metode BlackBox Testing. Black-Box Testing adalah model atau metode pengujian perangkat lunak yang difokuskan pada fungsionalitas dari perangkat lunak yang diuji. Sistem Informasi pengelolaan wisata edukasi ini sudah dilakukan pengujian pada fungsi operasionalnya. Adapun rencana pengujiannya diuraikan pada Tabel 6.

Setelah dilakukan pengujian, didapatkan hasil pengujian dari sistem informasi pengelolaan wisata edukasi secara keseluruhan. Hasil pengujian tersebut dapat dilihat pada Tabel 7.

Tabel 7. Tabel Hasil Pengujian

\begin{tabular}{|c|c|c|}
\hline User Requirement & Keterangan & Hasil \\
\hline URS-SIMWE-1 & Melakukan Login & Terpenuhi \\
\hline URS-SIMWE-2 & Tambah Admin & Terpenuhi \\
\hline URS-SIMWE-3 & Konfirmasi Calon Peserta & Terpenuhi \\
\hline URS-SIMWE-4 & Lihat data peserta & Terpenuhi \\
\hline URS-SIMWE-5 & Edit data peserta & Terpenuhi \\
\hline URS-SIMWE-6 & Hapus data peserta & Terpenuhi \\
\hline URS-SIMWE-7 & Lihat Pembayaran & Terpenuhi \\
\hline URS-SIMWE-8 & Tambah materi & Terpenuhi \\
\hline URS-SIMWE-9 & Edit materi & Terpenuhi \\
\hline URS-SIMWE-10 & Hapus materi & Terpenuhi \\
\hline URS-SIMWE-11 & Lihat Pembayaran & Terpenuhi \\
\hline URS-SIMWE-12 & Lihat hasil evaluasi & Terpenuhi \\
\hline URS-SIMWE-13 & Cetak laporan & Terpenuhi \\
\hline URS-SIMWE-13 & Melakukan login & Terpenuhi \\
\hline URS-SIMWE-14 & Konfirmasi Calon Peserta & Terpenuhi \\
\hline URS-SIMWE-15 & Lihat data peserta & Terpenuhi \\
\hline URS-SIMWE-16 & Edit data peserta & Terpenuhi \\
\hline URS-SIMWE-17 & Hapus data peserta & Terpenuhi \\
\hline URS-SIMWE-18 & Lihat Pembayaran & Terpenuhi \\
\hline URS-SIMWE-19 & Tambah materi & Terpenuhi \\
\hline URS-SIMWE-20 & Edit materi & Terpenuhi \\
\hline URS-SIMWE-21 & Hapus materi & Terpenuhi \\
\hline URS-SIMWE-22 & Lihat pembayaran & Terpenuhi \\
\hline URS-SIMWE-23 & Lihat hasil evaluasi & Terpenuhi \\
\hline URS-SIMWE-24 & Cetak laporan & Terpenuhi \\
\hline URS-SIMWE-25 & Pendaftaran & Terpenuhi \\
\hline URS-SIMWE-26 & Melakukan login & Terpenuhi \\
\hline URS-SIMWE-27 & Upload pembayaran & Terpenuhi \\
\hline URS-SIMWE-28 & Mendownload materi & Terpenuhi \\
\hline URS-SIMWE-29 & Input evaluasi & Terpenuhi \\
\hline
\end{tabular}

\section{KESIMPULAN}

Penelitian ini telah mengembangkan sistem informasi pengeloan wisata edukasi Kampung Markerter. Dari penelitian yang sudah dilakukan, dapat diambil kesimpulan bahwa dengan adanya Sistem Informasi 
Pengelolaan Wisata Edukasi Berbasis Web Studi Kasus Kampung Marketer Purbalingga dapat digunakan untuk mempermudah dalam mengelola Program Wisata Edukasi, hal ini dapat dibuktikan dari hasil pengujian yang membuktikan bahwa sistem telah bekerja sesuai dengan kebutuhan pengguna yang telah ditentukan. Sebagai saran untuk pengembangan sistem ke depan, sistem ini dapat dikembangkan dalam versi mobile untuk memudahkan calon peserta.

\section{DAFTAR PUSTAKA}

[1] L. Afuan, I. Permadi, and N. Hidayat, "Rancang Bangun Aplikasi Berbasis Teknologi Wap Sebagai Media Promosi Komoditas Pariwisata Di Banyumas,” J. Telemat., vol. 2, no. 2, pp. 12-34, 2009.

[2] L. Afuan, "Pemanfaatan Framework Codeigniter Dalam Pengembangan Sistem Informasi Pendataan Laporan Kerja Praktek Mahasiswa Program Studi Teknik Informatika Unsoed (Codeigniter Framework Used in Information System Development for Student's Report Data Collection Prac,” Juita, vol. I, pp. 39-44, 2010.

[3] Kamil, "Pembangunan Sistem Informasi Pelayanan Jasa Laundry Berbasis Web Dengan Fitur Mobile Pada 21 Laundry Padang," Semin. Nas. Sains dan Teknol. Fak. Tek. Univ. Muhammadiyah Jakarta, vol. 8, no. November, pp. 1-9, 2016, [Online]. Available: https://media.neliti.com/media/publications/172316-ID-pembangunan-sistem-informasi-pelayanan-j.pdf.

[4] R. S. Hidayat and A. Winarno, "Perancangan Sistem Informasi Pelayanan Jasa Laundry Pada Hello Laundry," Udinus, pp. 1-5, 2014, [Online]. Available: http://mahasiswa.dinus.ac.id/docs/skripsi/jurnal/14246.pdf.

[5] R. Fauzi, S. Wibowo, and D. Y. Putri, "Perancangan Aplikasi Marketplace Jasa Percetakan Berbasis Website,” Fountain Informatics J., vol. 3, no. 1, p. 5, 2018, doi: 10.21111/fij.v3i1.1824.

[6] A. Lasmedi and I. Permadi, "Rancang Bangun Sistem Infomasi Laboratorium (SILAB) Berbasis WEB Di Teknik Informatika UNSOED,” Pros. SNST Fak. Tek., vol. 1, no. 1, pp. 26-32, 2013.

[7] L. Afuan, A. Ashari, and Y. Suyanto, "The Ontology Approach for Information Retrieval in Learning Documents," J. Theor. Appl. Inf. Technol., vol. 97, no. 7, 2019.

[8] L. Afuan, "Sentimen Analisis Di Twitter ( Studi Kasus : Resepsi Pernikahan Putri Presiden Ri Ke-7 )," Semin. Nas. Teknol. Inf. dan Multimed., no. November 2017, pp. 1-6, 2018.

[9] L. Afuan, A. Ashari, and Y. Suyanto, "A study: query expansion methods in information retrieval," $J$. Phys. Conf. Ser., 2019, doi: 10.1088/1742-6596/1367/1/012001.

[10] R. S. Pressman, Rekayasa Perangkat Lunak Pendekatan Praktisi Edisi 7 (Buku Satu). Andi, 2010.

[11] I. A. Tiawan and L. Afuan, "Aplikasi Pengelolaan Kerjasama Pembuatan Projek Pada Dinas Komunikasi dan Infromatika Banyumas," J. Tek. Inform., vol. 1, no. 1, pp. 13-18, 2020.

[12] A. Nugroho, "Perancangan dan Implementasi Sistem Basis Data," Andi, 2011.

[13] A. Kadir, Pengenalan Sistem Informasi. Yogyakarta: Andi, 2003.

[14] Andhi Prasetio, Buku Pintar Pemrograman Web. Media Kita, 2012. 